\title{
Brief an Ignazio Cassis
}

\section{Jean Martin}

PD Dr. med., ehemaliger Kantonsarzt Waadt, Mitglied der Redaktion

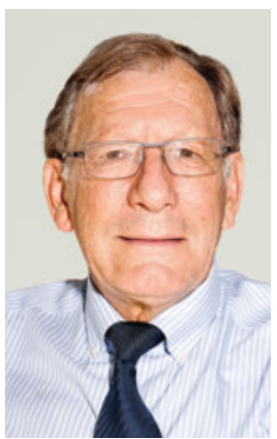

1 Vgl. den Art. «Juges étrangers: une attaque contre l'indépendance de la justice», Prof. Yves Sandoz. Le Temps, 12. September 2017, S. 10.

jean.martin[at]saez.ch
Lieber Ignazio

Wir kennen uns schon seit sehr langer Zeit, und unsere Beziehung gründet auf grosser Achtung und Freundschaft. Du bist Facharzt für Innere Medizin und Facharzt für Prävention und Gesundheitswesen. Acht Jahre hast Du unseren Fachverband Public Health Schweiz erfolgreich geleitet und daneben Lehraufträge wahrgenommen. Du bist Präsident der Stiftung Radix, eines Kompetenzzentrums für die Entwicklung von Massnahmen der öffentlichen Gesundheit. Seit fünf Jahren arbeiten wir gemeinsam im Vorstand von Curaviva. Und nicht zuletzt warst Du von 1996 bis 2008 ein ausgezeichneter Kantonsarzt im Tessin.

Nach zehn Jahren im Nationalrat wurdest Du nun in unsere Landesregierung gewählt. Dazu gratuliere ich Dir herzlich! Mit diesem Brief möchte ich Dir - in aller Bescheidenheit - die guten Wünsche eines alten, ebenfalls der FDP angehörigen Kollegen übermitteln (ich zähle mich zu den alten, in der «extremen Mitte» positionierten Liberal-Radikalen des Kantons Waadt). Nach all den erwarteten, "angemessenen» Dingen, die Du geäussert hast und die es zu sagen gilt, wenn man gewählt werden will, hoffe ich sehr darauf, dass Du - im Dienste der Nation - die Position des Staatsmannes übernimmst. Damit meine ich, dass Du Stärke zeigst und zum Wohle aller in unserem Lande handelst, auch wenn Du damit kritische Stimmen provozierst.

Die Medien sprechen von Deinem «Rechtsrutsch», und ich stimme ihnen zu. In den letzten Jahren hast Du in meinen Augen öfter zu neoliberale Positionen vertreten. Der Rahmen dieses Briefs reicht nicht aus, um näher auf Deine Verbindungen zu den grossen Versicherungen innerhalb der Curafutura einzugehen. Vor vier Jahren hast Du dazu eine Erklärung vor den Delegierten von Curaviva abgegeben. Sie fürchteten zu starke Interessenskonflikte - eine Befürchtung, die vor kurzem wieder auftauchte. Ich weiss, dass Du eine vernünftige, besonnene Gesundheitspolitik anstrebst, die die verschiedenen Interessengruppen ausgewogen berücksichtigt. Die Versicherer sollten sich nicht wie gewinnmaximierende Kapitalisten verhalten; gleichzeitig sollten die Ärzte und die anderen Partner jedoch mit gesundem Menschenverstand agieren und das Allgemeinwohl im Auge behalten. Dein Rücktritt aus dem Zentralvorstand der FMH im Jahr 2012, mit dem Du auf die unangemessen korporatistische Haltung der Mehrheit der Ärzteschaft zur integrierten Versorgung reagiert hast, war ein mutiger Schritt.
Du beweist auch Mut - auch wenn Deine Haltung offen gesagt die einzig vernünftige ist -, indem Du Dich für eine moderne Drogenpolitik einsetzt, die sich in Richtung einer Regulierung jener Produkte bewegt, die gegenwärtig in realitätsfremder Weise verteufelt werden. Dies ist nicht leicht in unserem Land. Dank würde Dir aber auch gebühren, wenn Du verständlich machen könntest, dass alle Substanzen mit Abhängigkeitspotential gleich zu behandeln und somit auch der Alkohol und der Tabak entsprechend zu regulieren sind. Speziell in Bezug auf den Tabak ist noch anzumerken, dass all jene, die sich für die öffentliche Gesundheit engagieren, es als inakzeptabel, ja als beschämend empfinden, wie sich die FDP-Fraktion dem Entwurf zum Tabakproduktegesetz widersetzt hat. Ihr habt Euch als Diener der Lobbyisten erwiesen, die sich dogmatisch weigern, den Zugang zu Produkten einzuschränken, die jedes Jahr zehntausend Schweizer in den Tod führen. Die Argumentation dieser Lobbyisten lässt sich leicht demontieren: Die Wahlfreiheit der Bürger wird nicht durch diejenigen eingeschränkt, die sich für die öffentliche Gesundheit einsetzen, sondern durch die Tabakhersteller, die - wie wir alle wissen - grosse Mittel aufwenden, um indiskutable wissenschaftliche Daten durch dauernde PR-Berieselung zu diskreditieren. Sie sind die gefährlichen Ajatollahs. Wirst Du uns in den kommenden Jahren nachdrücklich zeigen, dass Du nicht oder nicht mehr ihr Freund bist?

Und noch ein wichtiger Punkt: die riesigen Herausforderungen in Bezug auf die Umwelt und den Klimawandel. Sie betreffen unseren gesamten Planeten und die Lebensqualität der folgenden Generationen. Es wäre schön, wenn Du darauf hinwirken könntest, dass die Schweiz in dieser Hinsicht auf nationaler und internationaler Ebene eine beispielhafte Rolle einnimmt.

Ich schliesse mit Europa! Ich war und bin immer noch fest davon überzeugt, dass die enge Zusammenarbeit mit der EU (einschliesslich einer Art Rahmenvertrag) der einzig gangbare und angemessene Weg für unser Land ist. Um es offen zu sagen: Trotz der opportunistischen Erklärungen der Kandidaten für den Bundesrat ist die Kampagne der Nationalisten gegen "fremde Richter" verwerflich, ein weiteres taktisches Manöver der Politik. ${ }^{1}$

Alle meine guten Wünsche begleiten Dich, lieber Ignazio. Man weiss es wohl: "On ne gouverne qu'au centre.» Ich wage es, Dich daran zu erinnern. Und ich bin dankbar, wenn Du deine berufliche Herkunft, die Gesundheit, die Medizin und die Pflege, nicht vergisst. 